\title{
Diagnostic delay in oral squamous cell carcinoma: the role of cognitive and psychological variables
}

\author{
Vera Panzarella $^{1}$, Giuseppe Pizzo ${ }^{1}$, Francesco Calvino ${ }^{1}$, Domenico Compilato ${ }^{1}$, Giuseppe Colella ${ }^{2, *}$ \\ and Giuseppina Campisi ${ }^{1, *}$
}

This retrospective study investigated, in two cohorts of subjects living in Southern Italy and awaiting treatment for oral squamous cell carcinoma (OSCC), the variables related to diagnostic delay ascribable to the patient, with particular reference to the cognitive and psychological ones. A total of 156 patients with OSCC (mean age: 62 years, M/F: $2.39: 1$ ) were recruited at the Universities of Palermo and Naples. Risk factors related to patient delay included: sociodemographic, health-related, cognitive and psychological variables. The analysis was conducted by considering two different delay ranges: dichotomous ( $\leqslant 1$ month vs. $>1$ month) and polytomous ( $<1$ month, 1-3 months, $>3$ months) delay. Data were investigated by univariate and multivariate analyses and a $P$ value $\leqslant 0.05$ was considered statistically significant. For both delay measurements, the most relevant variables were: 'Personal experience of cancer' (dichotomous delay: $P=0.05$, odds ratio $(\mathrm{OR})=0.33,95 \%$ confidence interval $(\mathrm{Cl})=0.11-0.99$; polytomous delay: $P=0.006$, Chi-square $=10.224$ ) and 'Unawareness' (dichotomous delay: $P<0.01,0 R=4.96,95 \% \mathrm{Cl}=2.16-11.37$; polytomous delay: $P=0.087$, Chi-square $=4.77)$. Also 'Denial' $(P<0.01, \mathrm{OR}=6.84,95 \% \mathrm{Cl}=2.31-20.24)$ and 'Knowledge of cancer' $(P=0.079$, Chi-square $=8.359$ ) were found to be statistically significant both for dichotomous and for polytomous categorization of delay, respectively. The findings of this study indicated that, in the investigated cohorts, the knowledge about cancer issues is strongly linked to the patient delay. Educational interventions on the Mediterranean population are necessary in order to increase the patient awareness and to emphasize his/her key role in early diagnosis of OSCC.

International Journal of Oral Science (2013) 6, 39-45; doi:10.1038/ijos.2013.88; published 29 November 2013

Keywords: cognitive/psychological factors; diagnosis; oral squamous cell carcinoma; patient delay

\section{INTRODUCTION}

The oral squamous cell carcinoma (OSCC) is the most frequent malignant tumour of the oral cavity, covering more than $80 \%$ of all oral cancer diagnoses. Despite the progress in therapy, the mortality of patients with OSCC has remained steadily high during the last 20 years as compared to other cancers. Consequently, early diagnosis and treatment are still crucial to improve prognosis: if a correct diagnosis is made at the initial stage of the disease, the 5-year survival rate is higher than $90 \%{ }^{1}$

General practitioner and dental professionals must play an important role in secondary prevention of OSCC, but poor practice of the oral mucosa routine examination during dental and medical recalls is reported by almost all patients whose oral cancer was diagnosed at a late stage. Moreover, dentists should be responsible even for primary prevention of oral cancer, by giving advice on smoking cessation, alcohol diminution and sun protection. ${ }^{2-4}$

Besides the responsibilities ascribable to the professional ('provider delay'), another kind of liability has to be totally entrusted to the patient, which can be defined as 'patient delay', or alternatively as 'the period between the patient first noticing symptoms and their first consultation with a health care professional concerning those symptoms'. ${ }^{5-6}$

As for other cancers, patient delay accounts for approximately $60 \%$ of the overall diagnostic delay ${ }^{7}$ and it seems to be mainly related to cognitive and psychosocial variables. ${ }^{8-9}$ In a review of 32 qualitative investigations on cancer patients' experiences of help-seeking, Smith and colleagues ${ }^{10}$ concluded that the most common causes of patient delay are fear and lack of symptom recognition. Similar findings are reported in studies investigating the risk factors of the delay ascribable to the patients with head and neck/upper gastrointestinal cancers, with particular reference to cognitive and psychosocial variables, which are well known for being related to the detection of cancer symptoms and to seeking medical help. ${ }^{11-13}$

About $30 \%$ of OSCC patients usually wait for more than 3 months before consulting medical/dental professional after self-discovery of signs and symptoms of oral cancer. ${ }^{5,14}$ This delay is related to the difficulty experienced by patient in perceiving such signs and symptoms as harmful, whereas they are usually dismissed as a minor oral disease, e.g., trauma, infective process, disorders related to dentures or other generic, non-dangerous dental conditions. ${ }^{15}$

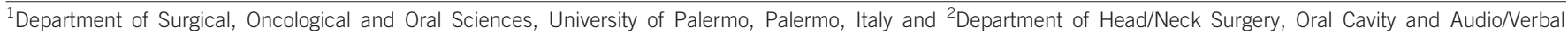
Communication, Second University of Naples, Naples, Italy

*Both authors contributed equally to this manuscript

Correspondence: Dr G Campisi, Department of Surgical, Oncological and Oral Sciences, University of Palermo, Via del Vespro 129, Palermo 90127, Italy

E-mail: campisi@odonto.unipa.it

Accepted 26 June 2013 
The understanding of the reasons that characterize the duration of this cognitive pathway is critical in order to design targeted intervention strategies. To the best of our knowledge, research on this topic, with specific reference to oral cancer, is scant, purely theoretical and qualitatively insufficient. ${ }^{8}$

The main aim of this retrospective study on OSCC patients was to investigate the variables related to patient delay, with particular reference to cognitive and psychological factors.

\section{SUBJECTS AND METHODS}

\section{Study design}

A total of 156 patients with histological diagnosis of SCC of the oral cavity and awaiting treatment were consecutively and unselectively recruited at the Department of Surgical, Oncological and Oral Sciences (Oral Medicine Unit), University of Palermo, and at the Department of Head/Neck Surgery, Oral Cavity and Audio/Verbal Communication, Second University of Naples, from January 2000 to December 2005. The study design was approved by the Ethical Committee of the University of Palermo. Informed consent was obtained from all the patients.

All subjects were interviewed, by two of the authors (Vera Panzarella and Giuseppina Campisi), using a structured, pre-tested questionnaire. ${ }^{16}$ Sociodemographic variables recorded during the interview included age, gender, level of education, employment, marital status and place of residence. In order to assess health-related variables, the subjects were interviewed about their smoking/drinking habits and regularity of dental attendance. Patients were divided into two groups according to their smoking/drinking status: smokers vs. non-smokers and non-drinkers $v$. drinkers, respectively. Patients claiming to have quit their smoking or drinking habits have been classified as 'former' smokers or drinkers, respectively. Finally, dental attendance was defined as regular when the subjects claimed to have undergone dental visit at least once a year.

Cognitive variables were also assessed, specifically including relatives' and personal experience of cancer, knowledge of cancer (either general or oral), experience of symptoms (with reference to asymptomatic or symptomatic lesions, in terms of experienced pain, burning, bleeding/ haemorrhage, swelling or irritation/tenderness), initial self-diagnosis (cancer, non-threatening condition, unable to self-diagnose) or complete unawareness (patient unable to recognize symptoms as such).

Finally, the interview considered some common psychological variables related to possible emotional responses to the detection of potentially threatening oral symptoms (denial, fear, carelessness, medical service mistrust).

Since interpretation of the symptoms could significantly differ depending on the considered district (e.g., oral vs. oropharyngeal), we exclusively recruited patients with SCC of the oral cavity (lip and oral sites: ICD-9 140, 141, 143-5) in order to select a cohort as homogeneous as possible.

The patients were specifically asked to provide their most reliable estimate about the date when they recalled to have experienced the first sign/symptom of OSCC. Patient delay was estimated by calculating the time interval between the provided information and the date when the first medical opinion for cancer-related sign/symptom was sought (as established by a physician, a dentist or a staff member at the Universities of Palermo and Naples). In accordance to this definition of delay, patients who did not notice any sign/symptom and did not seek medical consult (i.e., patients whose lesions were accidentally discovered) have been excluded from the study. In order to reduce both the 'classification bias' and the 'memory bias' related to patient delay, we decided to use two arbitrary categorizations of this quantity by choosing two different time points to discriminate between delayed and non-delayed cases: $\leqslant 1$ month vs. $>1$ month for dichotomous delay (using a cutoff of more than 30 days), and $<1$ month, 1-3 months, $>3$ months for polytomous delay.

\section{Statistical analysis}

Data were analysed by means of the computer package SPSS 15 (SPSS, Chicago, IL, USA). The Chi-square test was used to assess statistical differences among categorical variables, whereas Fisher's exact test was used when the observed frequency was less than 5; $P$ values $\leqslant 0.05$ were considered as statistically significant. In order to measure the association level, crude odds ratio (OR) and the 95\% corresponding test-based confidence interval (CI) were calculated. Reference groups were chosen as follows: for ordinal variables, the first category was chosen as the reference one; for other features, the category with the largest number was chosen as the reference one.

A logistic/multinomial regression model was also built for dichotomous/polytomous measurements of patient delay, respectively. The maximum likelihood estimates and adjusted odds ratio were obtained on full models by using the iterative weighted least squares procedure.

\section{RESULTS}

The male patients were $110(70.5 \%)$, while the female ones were 46 $(29.5 \%)$, with a male/female ratio equal to $2.39: 1$. The mean age at detection of oral signs and symptoms was (62 \pm 12.5$)$ years (age range: $32-92$ years). The patients were subdivided into four categories of age, according to 25 th, 50th and 75 th percentiles $(<51$, $<64,<72, \geqslant 72$ ).

No statistical significant association $(P>0.05)$ was found between sociodemographic/health-related variables and patient delay, with the exception of age in univariate analysis of polytomous measurement of delay $(P=0.001)$.

\section{Dichotomous measurement of patient delay ( $\leqslant 1$ month $v s .>1$ month)}

The patients characterized by delay $\leqslant 1$ month were $55 / 156$; those with delay $>1$ month were $101 / 156$ (35.3\% vs. 64.7\%). The univariate analysis results are reported in Table 1 . The most meaningful factors were: 'Personal experience of cancer' (Yes vs. None: $\mathrm{OR}=0.30$, 95\% CI $=0.11-0.82, P=0.02$ ), 'Knowledge of cancer' (Poor vs. Basic:

Table 1 Univariate analysis of dichotomous measurement of delay ( $\leqslant 1$ month vs. $>1$ month)

\begin{tabular}{|c|c|c|c|c|}
\hline Variables & $>1$ month & $\leqslant 1$ month & OR $(95 \% \mathrm{Cl})$ & $P$ value \\
\hline \multicolumn{5}{|c|}{ Sociodemographic and health-related variables } \\
\hline \multicolumn{5}{|l|}{ Age/years } \\
\hline$<51$ & 23 & 12 & 1.0 (ref) & \\
\hline$<64$ & 21 & 21 & $0.53(0.22-1.31)$ & 0.17 \\
\hline$<72$ & 29 & 7 & $2.11(0.74-5.99)$ & 0.16 \\
\hline$\geqslant 72$ & 28 & 15 & $0.97(0.38-2.47)$ & 0.96 \\
\hline
\end{tabular}


Table 1 Continued

\begin{tabular}{|c|c|c|c|c|}
\hline Variables & $>1$ month & $\leqslant 1$ month & OR $(95 \% \mathrm{Cl})$ & $P$ value \\
\hline \multicolumn{5}{|l|}{ Gender } \\
\hline Female & 32 & 14 & $1.36(0.65-2.84)$ & 0.42 \\
\hline Male & 69 & 41 & 1.0 (ref) & \\
\hline Uneducated & 5 & 4 & $0.49(0.11-2.20)$ & 0.35 \\
\hline Primary & 44 & 18 & 1.0 (ref) & \\
\hline Middle & 26 & 20 & $0.53(0.24-1.18)$ & 0.12 \\
\hline \multicolumn{5}{|l|}{ Employment } \\
\hline Clerk & 24 & 15 & $0.84(0.37-1.9)$ & 0.68 \\
\hline Farmer & 3 & 0 & $4.65(0.40-53.86)$ & 0.22 \\
\hline Professional & 1 & 4 & $0.15(0.02-0.96)$ & 0.04 \\
\hline Unemployed & 7 & 6 & $0.61(0.18-2.1)$ & 0.43 \\
\hline Retired & 40 & 21 & 1.0 (ref) & \\
\hline \multicolumn{5}{|l|}{ Place of residence } \\
\hline Rural district & 7 & 4 & $0.95(0.25-3.56)$ & 0.94 \\
\hline Small town (10-30 000 population) & 24 & 18 & $0.73(0.33-1.59)$ & 0.42 \\
\hline Medium town (30-150 000 population) & 24 & 8 & $1.59(0.65-3.87)$ & 0.30 \\
\hline Large town (>150 000 population) & 46 & 25 & 1.94 (ref) & \\
\hline \multicolumn{5}{|l|}{ Tobacco use } \\
\hline Smoker & 54 & 35 & 1.0 (ref) & \\
\hline Non-smoker & 29 & 13 & $1.43(0.67-3.05)$ & 0.35 \\
\hline Former user & 18 & 7 & $1.62(0.65-4.05)$ & 0.30 \\
\hline \multicolumn{5}{|l|}{ Alcohol consumption } \\
\hline Drinker & 47 & 28 & $0.91(0.47-1.75)$ & 0.77 \\
\hline Non-drinker & 50 & 27 & 1.0 (ref) & \\
\hline \multicolumn{5}{|l|}{ Personal experience of cancer } \\
\hline Yes & 7 & 11 & $0.30(0.11-0.82)$ & 0.02 \\
\hline None & 94 & 44 & 1.0 (ref) & \\
\hline \multicolumn{5}{|l|}{ Knowledge of cancer } \\
\hline Basic & 64 & 47 & 1.0 (ref) & \\
\hline None & 13 & 3 & $2.67(0.92-7.76)$ & 0.07 \\
\hline Poor & 24 & 5 & $2.91(1.25-6.76)$ & 0.013 \\
\hline \multicolumn{5}{|l|}{ Knowledge of oral cancer } \\
\hline Basic & 17 & 11 & $0.88(0.37-2.09)$ & 0.77 \\
\hline None & 65 & 37 & 1.0 (ref) & \\
\hline Poor & 19 & 7 & $1.51(0.61-3.72)$ & 0.37 \\
\hline \multicolumn{5}{|l|}{ Symptom experience } \\
\hline Symptomatic lesion & 80 & 38 & 1.0 (ref) & \\
\hline Asymptomatic lesion & 21 & 17 & $0.59(0.28-1.24)$ & 0.16 \\
\hline Initial self-diagnosis & & & & \\
\hline Non-threatening condition & 39 & 24 & $0.67(0.34-1.35)$ & 0.26 \\
\hline Cancer & 4 & 7 & $0.22(0.06-0.82)$ & 0.02 \\
\hline Unable to self-diagnose & 58 & 24 & 1.0 (ref) & \\
\hline Unawareness & & & & \\
\hline False & 37 & 32 & $0.42(0.21-0.81)$ & 0.01 \\
\hline True & 64 & 23 & 1.0 (ref) & \\
\hline Psychological variables & & & & \\
\hline Denial & & & & \\
\hline False & 75 & 48 & 1.0 (ref) & \\
\hline
\end{tabular}


Table 1 Continued

\begin{tabular}{|c|c|c|c|c|}
\hline Variables & $>1$ month & $\leqslant 1$ month & OR $(95 \% \mathrm{Cl})$ & $P$ value \\
\hline \multicolumn{5}{|l|}{ Fear } \\
\hline False & 94 & 52 & 1.0 (ref) & \\
\hline True & 7 & 3 & $1.29(0.32-5.20)$ & 0.72 \\
\hline \multicolumn{5}{|c|}{ Carelessness } \\
\hline False & 87 & 52 & 1.0 (ref) & \\
\hline True & 14 & 3 & $2.79(0.77-10.17)$ & 0.11 \\
\hline \multicolumn{5}{|c|}{ Medical service mistrust } \\
\hline False & 100 & 53 & 1.0 (ref) & \\
\hline True & 1 & 2 & $0.27(0.02-2.99)$ & 0.25 \\
\hline
\end{tabular}

$\mathrm{Cl}$, confidence interval; OR, odds ratio; n.d., not determined; ref, reference value.

Table 2 Logistic regression results of dichotomous measurement of delay ( $\leqslant 1$ month vs. $>1$ month)

\begin{tabular}{lcccc}
\hline Variables & $>1$ month & $\leqslant 1$ month & OR $(95 \% \mathrm{Cl})$ & $P$ value \\
\hline $\begin{array}{l}\text { Personal experience } \\
\text { of cancer }\end{array}$ & & & & \\
$\quad$ Yes & 7 & 11 & $0.33(0.11-0.99)$ & 0.05 \\
$\quad$ None & 94 & 44 & $1.0($ ref $)$ & \\
Unawareness & & & & \\
$\quad$ False & 37 & 32 & $4.96(2.16-11.37)$ & $<0.01$ \\
$\quad$ True & 69 & 41 & $1.0($ ref $)$ & \\
$\begin{array}{l}\text { Denial } \\
\text { False }\end{array}$ & 75 & 48 & $1.0($ ref $)$ & \\
$\quad$ True & 26 & 7 & $6.84(2.31-20.24)$ & $<0.01$ \\
\hline
\end{tabular}

$\mathrm{Cl}$, confidence interval; OR, odds ratio; ref, reference value.

$\mathrm{OR}=2.91,95 \% \mathrm{CI}=1.25-6.76, P=0.013$ in univariate analysis), 'Initial self-diagnosis' (Cancer vs. Unable to self-diagnose: $\mathrm{OR}=0.22,95 \% \mathrm{CI}=$ $0.06-0.82, P=0.02$ ), 'Unawareness' (False vs. True: $\mathrm{OR}=0.42,95 \% \mathrm{CI}=$
$0.21-0.81, P=0.01$ ) and 'Denial' (True vs. False: $\mathrm{OR}=2.38,95 \% \mathrm{CI}=0.96-$ 5.90, $P=0.06)$.

The logistic regression (Table 2) selected as most significant variables the following ones: 'Personal experience of cancer' (Yes vs. None: $\mathrm{OR}=0.33,95 \% \mathrm{CI}=0.11-0.99, P=0.05$ ), 'Unawareness' (True vs. False: $\mathrm{OR}=4.96,95 \% \mathrm{CI}=2.16-11.37, P<0.01$ ) and 'Denial' (True vs. False: $\mathrm{OR}=6.84,95 \% \mathrm{CI}=2.31-20.24, P<0.01$ ).

Polytomous measurement of patient delay ( $<1$ month, $1-3$ months, $>3$ months)

The patients characterized by delay $<1$ month were 55 (35.26\%), the ones with delay ranging from 1 month to 3 months were $51(32.69 \%)$, and finally, the ones with delay $>3$ months were $50(32.05 \%)$. The results of univariate analysis are reported in Table 3. The most meaningful variables are: 'Age' (Chi-square $=16.13, P=0.01$ ), 'Personal experience of cancer' (Chi-square $=6.79, P=0.03$ ), 'Knowledge of

Table 3 Univariate analysis of polytomous measurement of delay ( $<1$ month/1-3 months/ $>3$ months)

\begin{tabular}{|c|c|c|c|c|c|}
\hline Variables & $<1$ month & $1-3$ months & $>3$ month & OR $(95 \% \mathrm{Cl})$ & $P$ value \\
\hline \multicolumn{6}{|c|}{ Sociodemographic and health-related variables } \\
\hline Age/years & & & & 16.13 & 0.001 \\
\hline$<51$ & 12 & 11 & 12 & & \\
\hline$<64$ & 21 & 16 & 5 & & \\
\hline$<72$ & 7 & 15 & 14 & & \\
\hline$\geqslant 72$ & 15 & 9 & 19 & & \\
\hline Gender & & & & 0.80 & 0.67 \\
\hline Female & 14 & 17 & 15 & & \\
\hline Male & 41 & 34 & 35 & & \\
\hline Education & & & & 3.93 & 0.86 \\
\hline Uneducated & 4 & 3 & 2 & & \\
\hline Primary & 18 & 21 & 23 & & \\
\hline Middle & 20 & 14 & 12 & & \\
\hline Secondary & 8 & 10 & 9 & & \\
\hline Higher education & 5 & 3 & 4 & & \\
\hline Employment & & & & 14.04 & 0.30 \\
\hline Clerk & 15 & 14 & 10 & & \\
\hline Farmer & 0 & 1 & 2 & & \\
\hline Professional & 21 & 17 & 23 & & \\
\hline Unemployed & 6 & 4 & 3 & & \\
\hline Retired & 21 & 17 & 23 & & \\
\hline Other & 5 & 8 & 9 & & \\
\hline Marital status & & & & 2.43 & 0.30 \\
\hline Married/partner & 53 & 49 & 45 & & \\
\hline Unmarried/single & 2 & 2 & 5 & & \\
\hline Place of residence & & & & 5.48 & 0.48 \\
\hline Rural district & 4 & 2 & 5 & & \\
\hline
\end{tabular}


Table 3 Continued

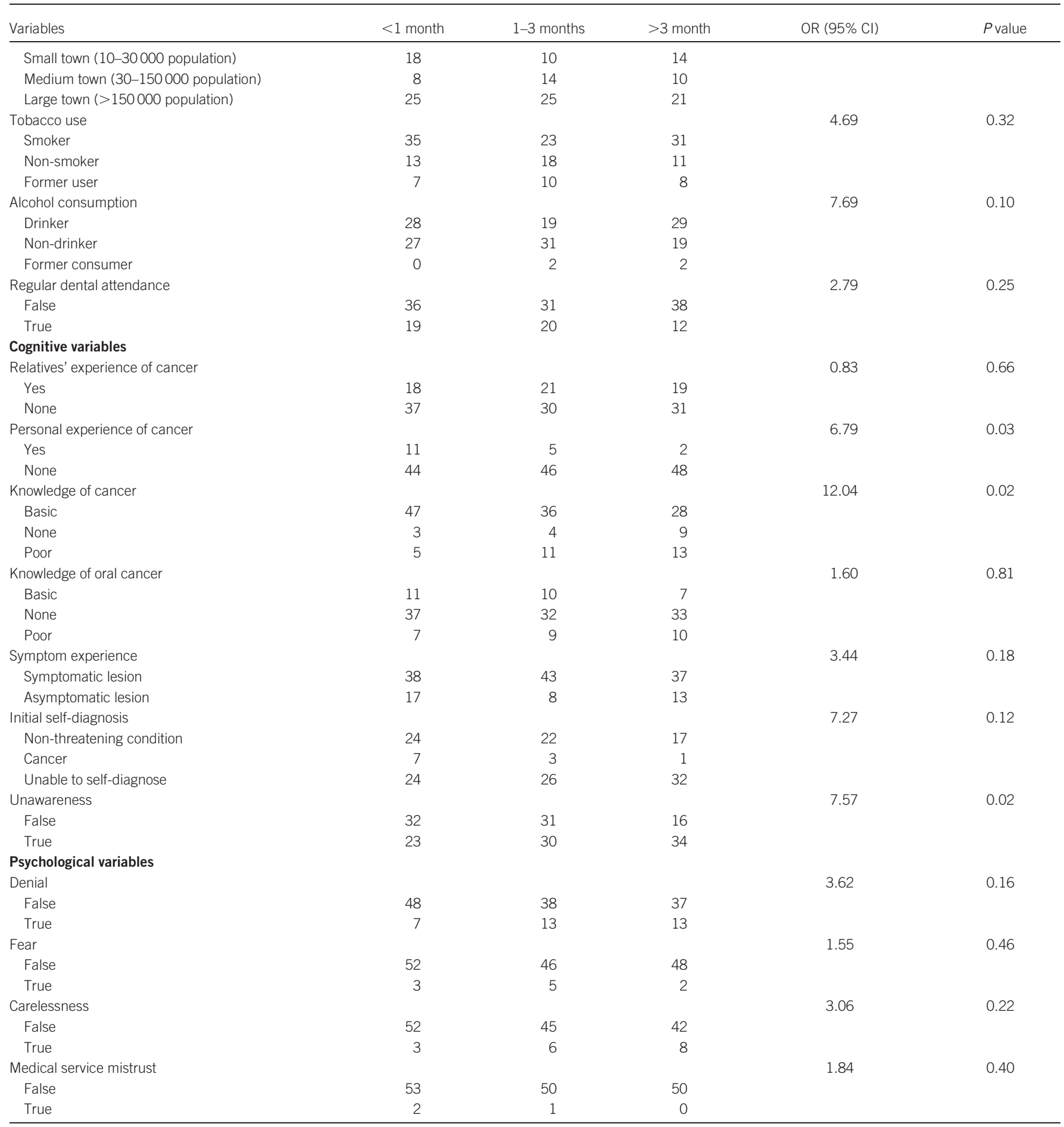

$\mathrm{Cl}$, confidence interval; $\mathrm{OR}$, odds ratio.

cancer' (Chi-square $=12.04, P=0.02)$ and 'Unawareness' (Chi-square $=$ 7.57, $P=0.02$ ).

As regards the results of multinomial regression (Table 4), the most meaningful variables were: 'Age' (Chi-square $=23.414, P=0.001$ ), 'Personal experience of cancer' (Chi-square $=10.224, P=0.006$ ), 'Knowledge of cancer' (Chi-square $=8.359, P=0.079$ ) and 'Unawareness' (Chi-square $=4.877, P=0.087$ ).
Table 4 Multinominal regression results of polytomous measurement of delay ( $<1$ month/1-3 months/ $>3$ months)

\begin{tabular}{lcc}
\hline Variables & Chi-square & $P$ value \\
\hline Age & 23.414 & 0.001 \\
Personal experience of cancer & 10.224 & 0.006 \\
Knowledge of cancer & 8.359 & 0.079 \\
Unawareness & 4.877 & 0.087 \\
\hline
\end{tabular}




\section{DISCUSSION}

With almost 130000 annual deaths worldwide, OSCC is considered a public health problem. ${ }^{17}$ This type of cancer is relatively common in Italy: in 2008, the registered incidence was equivalent to 4450 with an age-standardized rate per 100000 population per year equal to 6.0 for male and 2.3 for female. ${ }^{18}$ In Southern Italy, the number of new cases, in the same period, was 509 and age-standardized rate was 4.3 for male and 1.2 for female. ${ }^{19}$ The data on OSCC are still daunting: the majority of cases is identified late and in advanced clinical stage (i.e., III or IV). Moreover, after primary treatment, recidivists or metastases are found in more than half of the patients ( $80 \%$ of cases within the first two years) and the 5-year survival rate is less than $50 \% .{ }^{19}$ In these cases, the necessary surgical treatment and radio- and chemotherapy are so invasive, complex, weakening and disfiguring that they heavily compromise the quality of the remaining life. ${ }^{20-21}$

The great paradox of OSCC is that, despite the easy access to oral district for medical examination and the improvements on therapeutic approaches to the disease, its death rate remains high (approximately $46.5 \%$ ) and, even more unexpected, similar to that of cancers occurring in less accessible areas, such as colon, cervix and breast. ${ }^{22}$

OSCC is almost always preceded by visible and symptomatic early changes of the mucosa (such as ulcer, erithroplakia, leukoplakia), bleeding and pain. An adequate examination for the suspect of oral cancer consists of a simple, non-invasive, oral visual inspection that requires only $5 \mathrm{~min}$ during dental/medical recall. Nevertheless, the majority of patients are diagnosed at the late stage. ${ }^{23}$ Additionally, it seems that such oral examination is accepted by the patient with more hesitation than a pelvic exam and Pap smear. This patient behaviour is due to the misunderstanding of initial signs for minor oral diseases, such as trauma, infective process, disorders related to dentures or other dental condition. ${ }^{24-25}$ As a consequence, self- and/or inappropriate medications are carried out, in the false opinion of improving the course of the disease, while substantially increasing the duration of diagnostic delay.

Hence, an effective strategy to improve OSCC outcome and to reduce its morbidity seems to guide the patients towards an early diagnosis, by acting on those factors primarily involved in the initial stage of cognitive process. $^{7-8,16}$

In the present study, we investigated diagnostic delay in OSCC in two cohorts of patients living in Southern Italy and awaiting treatment for OSCC. To the best of our knowledge, this is the first study conducted in the Mediterranean area investigating the variables related to the patient delay, with particular reference to the cognitive and psychological ones.

No statistical significant association was found between lesion symptoms, sociodemographic (with the exception of age), healthrelated variables and patient delay. On the contrary, some of the cognitive and psychological variables investigated were found to be significantly associated with the diagnostic delay.

As regards dichotomous delay ( $\leqslant 1$ month vs. $>1$ month), the logistic regression showed the importance of 'Personal experience of cancer', 'Unawareness' and 'Denial' variables in terms of statistical significance. These results are similar to those obtained from the analysis conducted using a polytomous measurement of delay ( $<1$ month, 1-3 months, $>3$ months) that highlighted the 'Age', 'Personal experience of cancer', 'Knowledge of cancer' and 'Unawareness' variables.

Our findings also suggest that older patients with knowledge of cancer (through personal experience or referred) showed a smaller delay with respect to younger patients, whereas emotional response, such as denial, related to difficulty in recognizing potential cancer symptoms, was found to be significantly related to the OSCC delay.

These results could be explained by the consideration that the majority of people, particularly young subjects, with no experience of cancer (general or oral), very seldom consider the possibility to have a malignant disease. As a consequence, a 'wait and see' behaviour is adopted, denying the usefulness of medical help and opting for a useless self-diagnosing and/or a self-medication for an indefinite time.

Non-recognition of the severity of symptoms, mainly related to lack of knowledge about the disease, was the predominant risk factor for patient delay across all cancer sites, ${ }^{9}$ including the oral cavity where malignant conditions are almost always preceded by symptomatic early signs that could easily be diagnosed. ${ }^{4}$

With the limitation related to the retrospective design of the present study (that could be biased by patient difficulty to report specific time interval), the main results of the present investigation are in line with those of similar researches on other symptomatic cancers. ${ }^{26}$ Our findings also support the belief that improving basic knowledge about cancer issue may increase people's ability to identify cancer symptoms and to promote an appropriate life-saving help-seeking.

For this purpose, as recently recommended by Rogers et al., ${ }^{15}$ increasing public awareness, both on oral cancer and general cancer, by media advertising such as TV/radio broadcasts/newspapers/publications, and by regular educational programs involving schools, should be promptly planned. The use of alert messages in dental/ general practitioners and pharmacies may also be useful to increase the population awareness on the high variability of presentation of the OSCC. ${ }^{26}$

These intervention strategies should be conducted by emphasizing the key role of the patient on the diagnostic pathway of oral cancer. In fact, as suggested by Austoker et al., ${ }^{27}$ awareness interventions, knowledge of screening visits and their time interval (6-12 months in asymptomatic subjects), self-checking behaviour are considered important elements of cancer awareness. Therefore, similarly to the promotion of breast self-examination or testicular checking, which are reported as helpful in the reduction of breast and testicular cancers, respectively, the self-examination of the oral cavity should be strongly encouraged, as this can enable the patient to detect early OSCC signs. $^{8,28}$

In conclusion, the findings of this study indicated that, in the investigated cohorts, the knowledge about cancer issues is strongly linked to the patient delay. Educational interventions on the Mediterranean population are necessary in order to increase the patient awareness and to emphasize his/her key role in early diagnosis of OSCC.

1 Gao W, Guo CB. Factors related to delay in diagnosis of oral squamous cell carcinoma. J Oral Maxillofac Surg 2009; 67(5): 1015-1020.

2 Mignogna MD, Fedele S, Lo Russo $L$ et al. Oral and pharyngeal cancer: lack of prevention and early detection by health care providers. Eur J Cancer Prev 2001; 10(4): 381-383.

3 Seoane-Romero JM, Vazquez-Mahia I, Seoane J et al. Factors related to late stage diagnosis of oral squamous cell carcinoma. Med Oral Patol Oral Cir Bucal 2012; 17(1): e35-e40.

4 van der Waal I, de Bree R, Brakenhoff $\mathrm{R}$ et al. Early diagnosis in primary oral cancer: is it possible? Med Oral Patol Oral Cir Bucal 2011; 16(3): e300-e305.

5 Allison P, Locker D, Feine JS. The role of diagnostic delays in the prognosis of oral cancer: a review of the literature. Oral Oncol 1998; 34(3): 161-170.

6 Scott S, McGurk M, Grunfeld E. Patient delay for potentially malignant oral symptoms. Eur J Oral Sci 2008; 116(2): 141-147.

7 Scott SE, McGurk M, Grunfeld EA. The process of symptom appraisal: cognitive and emotional responses to detecting potentially malignant oral symptoms. J Psychosom Res 2007; 62(6): 621-630. 
8 Gomez I, Warnakulasuriya S, Varela-Centelles PI et al. Is early diagnosis of oral cancer a feasible objective? Who is to blame for diagnostic delay? Oral Dis 2010; 16(4): 333342.

9 Macleod U, Mitchell ED, Burgess $C$ et al. Risk factors for delayed presentation and referral of symptomatic cancer: evidence for common cancers. Br J Cancer 2009; 101(Suppl 2): S92-S101.

10 Smith LK, Pope C, Botha JL. Patients' help-seeking experiences and delay in cancer presentation: a qualitative synthesis. Lancet 2005; 366(9488): 825-831.

11 Macdonald S, Macleod U, Campbell NC et al. Systematic review of factors influencing patient and practitioner delay in diagnosis of upper gastrointestinal cancer. $\mathrm{Br} J$ Cancer 2006; 94(9): 1272-1280.

12 Scott SE, Grunfeld EA, Auyeung $V$ et al. Barriers and triggers to seeking help for potentially malignant oral symptoms: implications for interventions. J Public Health Dent 2009; 69(1): 34-40.

13 Tromp DM, Brouha HD, Hordijk GJ et al. Patient factors associated with delay in primary care among patients with head and neck carcinoma: a case-series analysis. Fam Pract 2005; 22(5): 554-559.

14 Scott SE, Grunfeld EA, McGurk M. Patient's delay in oral cancer: a systematic review. Community Dent Oral Epidemiol 2006; 34(5): 337-343.

15 Rogers SN, Vedpathak SV, Lowe D. Reasons for delayed presentation in oral and oropharyngeal cancer: the patients perspective. Br J Oral Maxillofac Surg 2011; 49(5): 349-353.

16 Andersen R, Vedsted SP, Olesen F et al. Patient delay in cancer studies: a discussion of methods and measures. BMC Health Serv Res 2009; 9: 189.

17 Petti S. Diagnostic delay is not associated with advanced-stage oro-pharyngeal cancer. Eur J Oral Sci 2010; 118(2): 210-211; author reply 212

18 Ferlay J, Shin HR, Bray F et al. GLOBOCAN 2008 v2.0, cancer incidence and mortality worldwide: IARC CancerBase No. 10 [Internet]. Lyon: International Agency for Research on Cancer, 2010. Available at http://globocan.iarc.fr (accessed 13 January 2013).
19 Pitiphat W, DiehI SR, Laskaris G et al. Factors associated with delay in the diagnosis of oral cancer. J Dent Res 2002; 81(3): 192-197.

20 Johnson NW, Warnakulasuriya S, Gupta PC et al. Global oral health inequalities in incidence and outcomes for oral cancer: causes and solutions. Adv Dent Res 2011; 23(2): 237-246.

21 Villa A, Villa C, Abati S. Oral cancer and oral erythroplakia: an update and implication for clinicians. Aust Dent J 2011; 56(3): 253-256.

22 Petti S, Scully C. Oral cancer knowledge and awareness: primary and secondary effects of an information leaflet. Oral Oncol 2007; 43(4): 408-415.

23 Mignogna MD, Fedele S. Oral cancer screening: 5 minutes to save a life. Lancet2005; 365(9475): 1905-1906.

24 Mignogna MD, Fedele S, Lo Russo L. The world cancer report and the burden of oral cancer. Eur J Cancer Prev 2004; 13(2): 139-142.

25 Paleri V, Wight RG, Silver CE et al. Comorbidity in head and neck cancer: a critical appraisal and recommendations for practice. Oral Oncol 2010; 46(10): 712-719.

26 Simon AE, Waller J, Robb $\mathrm{K}$ et al. Patient delay in presentation of possible cancer symptoms: the contribution of knowledge and attitudes in a population sample from the United Kingdom. Cancer Epidemiol Biomarkers Prev 2010; 19(9): 2272-2277.

27 Austoker J, Bankhead C, Forbes LJ et al. Interventions to promote cancer awareness and early presentation: systematic review. Br J Cancer 2009; 101(Suppl 2): S31-S39.

28 Peacock ZS, Pogrel MA, Schmidt BL. Exploring the reasons for delay in treatment of oral cancer. J Am Dent Assoc 2008; 139(10): 1346-1352.

(c) This work is licensed under a Creative Commons

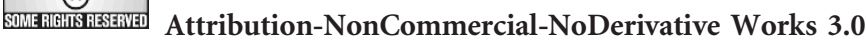

Unported License. To view a copy of this license, visit http:// creativecommons.org/licenses/by-nc-nd/3.0 